\title{
Colorimetric Solid-Phase Extraction Method for Cu(II) lon Determination Using 2-Hydroxybenzaldehyde Benzoylhydrazone as Sensing Reagent
}

\author{
Estrella Espada-Bellido,, ${ }^{\text {a,b }}$ Maria Dolores Galindo-Riaño, ${ }^{\text {a,* }}$ Manuel García-Vargas, ${ }^{a}$ \\ Ramaier Narayanaswamy ${ }^{b}$ \\ a Department of Analytical Chemistry, Faculty of Sciences, University of Cadiz, P.O. Box 11510, Campus Río S. Pedro, Puerto Real, \\ Cadiz 11510 Spain \\ ${ }^{\mathrm{b}}$ Centre for Instrumentation and Analytical Science, School of Chemical Engineering and Analytical Science, The University of \\ Manchester, Manchester M60 1QD UK
}

A new sensor based on the use of 2-hydroxybenzaldehyde benzoylhydrazone as a colorimetric reagent immobilized onto styrenedivinylbenzene disks has been carried out for the determination of $\mathrm{Cu}$ (II) ions within several minutes. The sensor is designed on a rapid and easy two-step procedure: (1) the extraction of $\mathrm{Cu}$ (II) ions onto a disk loaded with the copper-selective colorimetric reagent and (2) the determination of the complexed analyte directly on the surface of the disk using diffuse reflectance measurements at $400 \mathrm{~nm}$. The color of the disk changed from white to green in the presence of $\mathrm{Cu}$ (II) ions. The work herein details the optimization of the sensing system employing a fractional factorial design $3^{3-1}$ considering three variables $(\mathrm{pH}$, immobilization time, and amount of ligand immobilized onto the disk). The Pareto chart and response surfaces in a spherical domain indicated that the optimum conditions for the sensing of copper ions were $\mathrm{pH}=7$, with a ligand immobilization time of $10 \mathrm{~min}$ and $6.25 \mathrm{mg}$ of reagent loaded onto the disk. Under the optimum conditions, the analytical parameters of the proposed method were determined. The calibration graph was linear over the range of 0 to $2.5 \mathrm{mg} \mathrm{L}^{-1}$ of $\mathrm{Cu}$ (II) with a detection limit of $0.21 \mathrm{mg} \mathrm{L}^{-1}$. The relative standard deviation for six measurements of $1 \mathrm{mg} \mathrm{L}^{-1}$ of $\mathrm{Cu}$ (II) was found to be $4.87 \%$. The interference from inorganic salts and other metals was found not to be of major concern when monitoring copper ions in water samples. The simplicity and rapidity of this technique make it convenient and amenable for on-site and routine analysis.

Index Headings: Copper; Sensing; Colorimetric solid phase extraction; 2-Hydroxybenzaldehyde benzoylhydrazone; Diffuse reflectance spectroscopy; Green chemistry.

\section{INTRODUCTION}

Copper plays an important role as an essential trace element for human beings in various physiological processes. Indeed, many clinical disorders can be associated with the deficiency of copper, such as anemia, gastrointestinal disturbances, or even heart failure. ${ }^{1,2}$ However, this metal represents an environmental concern when it is present in uncontrolled amounts exceeding the nutritional requirements. The allowed limit of copper in drinking water is set to $2 \mathrm{mg} \mathrm{L}^{-1}$ by the European Commission, ${ }^{3} 1.3 \mathrm{mg} \mathrm{L}^{-1}$ as primary standard (maximum contaminant level goal), and $1.0 \mathrm{mg} \mathrm{L}^{-1}$ as

Received 28 May 2013; accepted 6 November 2013

* Author to whom correspondence should be sent. E-mail: dolores. galindo@uca.es.

DOI: $10.1366 / 13-07126$ secondary standard (non-enforceable guidelines but with cosmetic effects or esthetic effects) by the U.S. Environmental Protection Agency (EPA). ${ }^{4}$ The U.S. National Oceanic and Atmospheric Administration screening quick reference tables present a secondary maximum contaminant level of $1.3 \mathrm{mg} \mathrm{L}^{-1}$ applicable to ground water. ${ }^{5}$ A high concentration of copper in water originates mainly from fungicide residues containing this metal used in agriculture, corrosion of household plumbing systems, or erosion of natural deposits. For this reason, aquatic sites contaminated with this metal must be monitored regularly.

Conventional methods for measuring copper in aqueous environments are usually time consuming, the sample handling and processing steps are labor intensive, and the water sample is often processed days or even weeks after collection. This time lag between sampling and analysis necessitates the addition of some preservatives for sample storage. Furthermore, traditional analytical procedures require considerable quantities of chemical compounds and frequently involve the formation of large amounts of pollutants during the preparation of the samples. Thus, the incorporation of green chemistry rules in the laboratory is desirable. ${ }^{6,7}$ One of the best strategies to solve these problems is the development of on-site and real time analysis with environmentally friendly devices that are also highly miniaturized. ${ }^{8}$ The use of chemical sensors has made an important contribution to this field, allowing the analyst to bring the laboratory to the sample instead of taking the sample to the laboratory. ${ }^{9}$ Optical sensors that make use of polymer membranes containing a reagent that reacts with the analyte to produce a distinctive color change have been well established for the trace analysis of heavy metal ions, among other applications. ${ }^{10}$ As mentioned earlier, miniaturization is one way to avoid some of the negative side effects that are often encountered in analytical methods, and miniaturization has been the subject of a significant number of research efforts. In this respect, a combination of a modern analytical technique with miniaturization allows the development of powerful analytical devices for the effective control of processes and pollution. ${ }^{11}$

Colorimetric solid phase extraction (C-SPE) has received special attention over the last few years because it meets many of the requirements mentioned earlier. ${ }^{12}$ This methodology involves the extraction of 
TABLE I. Review of some recent reflectance sensor systems for the determination of metal ions.

\begin{tabular}{|c|c|c|c|}
\hline Reference & Reagent $^{\mathrm{a}}$ & Metal & Support matrix \\
\hline Gazda et al., 2004 ${ }^{14}$ & DMG & $\mathrm{Ni}(\mathrm{II})$ & SDB-XC \\
\hline Filik et al., $2009^{16}$ & $\mathrm{PHZ}$ & $\mathrm{Mo}(\mathrm{VI})$ & XAD-16 \\
\hline Arena et al., $2003^{17}$ & DMABR & $\mathrm{Ag}(\mathrm{I})$ & SDB-XC \\
\hline Mahendra et al., $2003^{18}$ & Cupron & $\mathrm{Cu}(\mathrm{II})$ & XAD-2 \\
\hline Fritz et al., $2003^{19}$ & Zn DTC & $\mathrm{Cu}(\mathrm{II})$ & SDB-XC \\
\hline Filik and Yanaz, $2009^{20}$ & PAN & $\mathrm{V}(\mathrm{V})$ & XAD-16 \\
\hline Hill et al., $2010^{21}$ & DMABR & $\mathrm{Ag}(\mathrm{I})$ & SDB-XC \\
\hline Yanaz et al., $2010^{22}$ & ASA III & $\mathrm{Pb}(\mathrm{II})$ & XAD-16 \\
\hline Bradley et al., $2011^{23}$ & PVP & As(III) & SDB-XC \\
\hline This work & 2-HBBH & $\mathrm{Cu}(\mathrm{II})$ & SDB-XC \\
\hline
\end{tabular}

a DMABR, 5-(p-dimethylaminobenzylidene) rhodanine; Cupron, abenzoinoxime; Zn DTC, zinc diethyldithiocarbamate; DMG, dimethylglyoxime; PAN, 1-(2-pyridylazo)-2-naphtol; PHZ, phenylhydrazine; ASA III, 2,7-bis(2-arsenophenylazo) 1,8-dihydroxynaphthalene-3,6-disulphonic acid; PVP, poly(vinylpyrrolidone); $2 \mathrm{HBBH}$, 2-hydroxybenzaldehyde benzoylhydrazone; SDB-XC, polystyrene-divinylbenzene; XAD-2 and XAD-16, Amberlite polymeric adsorbent.

analytes onto a proper support impregnated with a colorimetric reagent and then quantified directly on the surface using diffuse reflectance spectroscopy (DRS). DRS is a valuable alternative for the study of the chemical changes that occur on the adsorbent surface of a solid by analyzing the radiation that returns from the sensing region. ${ }^{13-15}$ Thus, this technique can be an alternative for achieving green chemistry ambitions, because the elution step, necessary in the SPE, which requires high purity solvents, is eliminated from the process, and the amount of analyte is measured directly on the solid surface. In addition, the simplicity and rapidity of this technique make it convenient and amenable for on-site and routine analysis.

The sensor described in this paper relies on the selective SPE of $\mathrm{Cu}(\mathrm{II})$ ions from a water sample onto a disk loaded with a copper-selective colorimetric reagent. Then, the color change of single-use SPE membranes measured by DRS was used to determine the amount of copper extracted using the disk. ${ }^{16}$ To date, different organic reagents and solid supports have been applied to the development of the optical sensor employing diffuse reflectance measurements. Some of the most relevant and recent works related to this field are given in Table I. ${ }^{14,16-23}$ As can be seen here, papers based on the determination of copper have been rarely reported. The use of cupron ( $\alpha$-Benzoinoxime) and zinc(II) dithiocarbamates as selective ligands for the determination of copper have been described previously. ${ }^{18,19}$

Hydrazones have shown attractive potentialities for CSPE applications because of their donor properties in coordinating metals and their ability to behave as polydentate ligands. In our previous paper, 2-hydroxybenzaldehyde benzoylhydrazone (2-HBBH) solution has been described as a selective chemosensor for the determination of copper ions. ${ }^{24}$ To the best of our knowledge, this ligand has not been used previously as diffuse reflectance sensing layer for the determination of metal ions. Styrenedivinylbenzene (SDB-XC) membrane disks were employed as the sorbent material for $2-\mathrm{HBBH}$ immobilization. This type of sorbent for disks is useful for compounds poorly extracted by octadecylsiloxane-bond- ed silica sorbents and soluble in water. Also, SDB disks have the important advantage of being stable in the whole range of $\mathrm{pH}$, and the selectivity of the disks can be improved with the immobilization of suitable reagents onto the solid sorbent. ${ }^{25}$

Hence, the goal of this work was the development of a novel, simple, highly selective, portable, and costeffective sensor disk for the detection of copper ions in the aqueous environment with the combination of a rapid preconcentration technique and colorimetric chemistry detection using diffuse reflectance measurements. The $\mathrm{Cu}$ (II) sensor based on C-SPE was developed with aroylhydrazone as the selective reagent immobilized onto styrenedivinylbenzene polymer disks and a fiber optic to guide the light to and from the sensing area.

Preliminary studies of the influence of variables in the determination of copper ions were carried out with a flame atomic absorption spectrophotometer (FAAS) as the measurement technique after acid elution of metal ion from the disk. Once parameters had been evaluated, reflectance detection was used for the optimization process. A fractional factorial design $3^{3-1}$ considering three variables $(\mathrm{pH}$, immobilization time, and amount of ligand immobilized onto the disk) was employed for the optimization of the sensing system. Fluorescence measurements were also investigated as a comparison with the reflectance signals.

\section{EXPERIMENTAL}

Reagents. All reagents were of analytical-reagent or Suprapur grade, and all solutions were prepared with Millipore Milli-Q (USA) deionized water or extrapure ethanol.

The 2-hydroxybenzaldehyde benzoylhydrazone ${ }^{26}$ was synthesized by the reaction between 2-hydroxybenzaldehyde (2-HB) and benzoylhydrazine $(\mathrm{BH})$, purchased from Sigma-Aldrich (Steinhein, Germany; see Fig. 1). Ethanolic solution of 2-HB (1 mL in $20 \mathrm{~mL}$ ) and aqueous solution of $\mathrm{BH}(1.11 \mathrm{~g}$ in $30 \mathrm{~mL})$ were mixed. The complex formed from condensation was filtered and subsequently crystallized three times from 1:1 ethanol/water. The last yellow product obtained was dried in the oven at $50{ }^{\circ} \mathrm{C}$ for $6 \mathrm{~h}$. The stock solution of 2-HBBH in extrapure ethanol (Scharlab, Spain) was prepared weekly and stored at 4 ${ }^{\circ} \mathrm{C}$ in darkness. For the preliminary studies utilizing FAAS, $2.5 \mathrm{mg}$ of $2-\mathrm{HBBH}$ in $2.5 \mathrm{~mL}$ of ethanol was prepared. For diffuse reflectance studies, $6.25 \mathrm{mg}$ of $2-$ $\mathrm{HBBH}$ in $6.25 \mathrm{~mL}$ was used. As previously evaluated, ${ }^{24} \mathrm{a}$ $1: 1$ stable complex is formed between copper and 2$\mathrm{HBBH}$ in aqueous ethanolic solution. The ligand coordinates to the copper ion as a monoanionic, tridentate ligand through the phenolic oxygen, the imine nitrogen, and the amide oxygen. A square planar geometry can be proposed for this complex.

Stock aqueous solutions of $\mathrm{Cu}(\mathrm{II})$ were prepared weekly by the dilution of $\mathrm{Cu}$ (II) standard solution of $1000 \mathrm{mg} \mathrm{L}^{-1}$ (Merck, Darmstadt, Germany) in $0.06 \mathrm{~mol}$ $\mathrm{L}^{-1} \mathrm{HNO}_{3}$.

Hydrion phosphate Chemvelope buffers purchased from Sigma-Aldrich were used to adjust the $\mathrm{pH}$ (range 3-9) by adding to $500 \mathrm{~mL}$ of Milli-Q deionized water. This buffer and other different buffer solutions (Iisted below) 
<smiles>O=Cc1ccccc1O</smiles>

2-hydroxybenzaldehyde (2-HB)<smiles>NNC(=O)c1ccccc1</smiles>

benzoylhydrazine (BH)

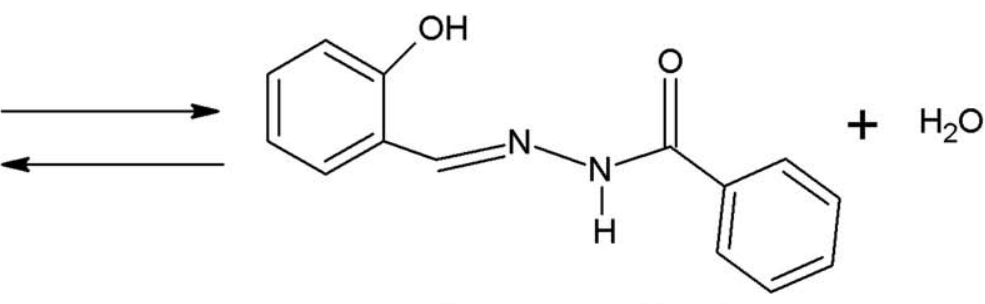

2-hydroxybenzaldehyde benzoylhydrazone (2-HBBH)

FIG. 1. The synthetic route of 2-hydroxybenzaldehyde benzoylhydrazone (2-HBBH).

were prepared and adjusted to $\mathrm{pH} 7$, which was chosen as the optimum $\mathrm{pH}: 0.5 \mathrm{~mol} \mathrm{~L}^{-1}$ HEPES from $\mathrm{N}-2-$ hydroxyethylpiperazine- $N^{\prime}$-2-ethane sulphonic acid (Sigma-Aldrich) and suprapur ammonia (Merck); $0.05 \mathrm{~mol}$ $\mathrm{L}^{-1}$ from piperazine- $N, N^{\prime}$-bis (ethanesulfonic acid) (PIPES) and suprapur ammonia (Merck); $1 \mathrm{~mol} \mathrm{~L}^{-1}$ suprapur ammonia (Merck), and $1 \mathrm{~mol} \mathrm{~L}^{-1}$ suprapur nitric acid (Merck); and $0.5 \mathrm{~mol} \mathrm{~L}^{-1}$ potassium dihydrogen phosphate $\left(\mathrm{KH}_{2} \mathrm{PO}_{4}\right)$ and $1 \mathrm{~mol} \mathrm{L^{-1 }} \mathrm{NaOH}$.

Apparatus. The FAAS used for the initial measurements of copper concentration using SPE was a Solaar M Series (Unicam, UK), operating under recommended conditions for $\mathrm{Cu}(\mathrm{II})$. Diffuse reflectance measurements were recorded using AvaSpec-PC2000 High UV-sensitivity CCD Spectrometer and an FCR-7UV200-2-45 reflection probe (Avantes), controlled using the software SpectraWin 4.2(c) 2000 (Top Sensor Systems). Fluorescence measurements were recorded with an LS 55 PerkinElmer Luminiscence Spectrometer (Waltham, MA) with excitation and emission slit widths set at 10 and $20 \mathrm{~nm}$, respectively. A Hanna Turtle $\mathrm{pH}$ meter was used for $\mathrm{pH}$ measurements.

Preparation of Modified Extraction Disks and Extraction Procedure. Empore SDB-XC (3M) polystyrene-divinylbenzene $47 \mathrm{~mm}$ extraction disks were used as the extraction membranes. The membrane disk was placed in the filtration apparatus (Millipore glass $47 \mathrm{~mm}$ vacuum filter holder assembly with $300 \mathrm{~mL}$ funnel with a glass fritted base) and washed with $10 \mathrm{~mL}$ of $1.0 \mathrm{~mol} \mathrm{~L}^{-1}$ nitric acid solution, $10 \mathrm{~mL}$ of methanol, and $10 \mathrm{~mL}$ of acetonitrile in order to remove the contaminants from the disk. After all the solvents had passed through the disk, it was dried using passing air for several minutes. Then, the membranes were cut into $13 \mathrm{~mm}$ disks with a cork borer. The small disk was placed on a $13 \mathrm{~mm}$ plastic Fisherbrand SyringeSwinnex Filter Holders (Millipore). A solution of 2-HBBH prepared by dissolving $6.25 \mathrm{mg}$ of reagent in $6.25 \mathrm{~mL}$ of ethanol was passed through the disk using a $5 \mathrm{~mL}$ plastic syringe attached to the holder (for diffuse reflectance measurements). After impregnation with 2-HBBH, the disk was dried for a few minutes and washed with $5 \mathrm{~mL}$ of water to pre-wet the surface of the disk. Then, $50 \mathrm{~mL}$ of the sample adjusted to $\mathrm{pH} 7$ with $0.05 \mathrm{~mol} \mathrm{~L}^{-1} \mathrm{KH}_{2} \mathrm{PO}_{4} / \mathrm{NaOH}$ buffer was passed through the modified membrane disk. The solution was pushed manually using the syringe at a rate of approximately one drop per second. This step required about $10 \mathrm{~min}$. After the extraction, $10 \mathrm{~mL}$ of air was passed through the holder to remove remaining sample solution. The holder was detached from the syringe and unscrewed, and the disk was removed from the holder. Finally, the optical fiber was placed in direct contact onto the disk in the dark to acquire the diffuse reflectance spectrum. It is important to highlight that no copper recovery was obtained without employing reagent onto the disk.

Diffuse Reflectance Measurement. The optical signal recorded using the detector as counts is indicative of diffuse reflectance of the incident light using the sensing membrane. The reflectance measurements of the disk surface were measured at $400 \mathrm{~nm}$, which was the maximum reflectance signal. The diffuse reflectance standard (a white material) used in the experiments was a bare polystyrene-divinylbenzene disk. For optical isolation, the fiber optic and the membrane disk were kept in a black box to minimize any interference from ambient light. Spectra data were transferred to the computer and downloaded to a Microsoft Excel worksheet to plot reflectance data.

Note that the diffuse reflectance $(R)$ at $400 \mathrm{~nm}$ was used to calculate the Kubelka-Munk function $F(R)$ using the expression:

$$
F(R)=\frac{(1-R)^{2}}{2 R}
$$

$F(R)$ can be directly related to the concentration of the complex in the membrane disk to obtain a linear calibration plot for quantitative measurements ${ }^{15}$ using the expression:

$$
F(R)=\frac{\varepsilon \cdot C}{S}
$$

where $\varepsilon$ is the molar absorptivity of the sample and $S$ is the scattering coefficient of the disk surface, both of which can be considered as constants in this work. The diffuse reflectance equipment employed in this work converts reflectance data to the Kubelka-Munk function, which is directly proportional to absorbance. For the remainder of this manuscript, the value of the KubelkaMunk function will be referred to as reflectance signal.

\section{RESULTS AND DISCUSSION}

Some preliminary experiments were carried out in order to investigate the quantitative retention of copper ions using the membrane disk in the absence and presence of $2-\mathrm{HBBH}$. It was found that the bare membrane disk did not show any tendency for the 


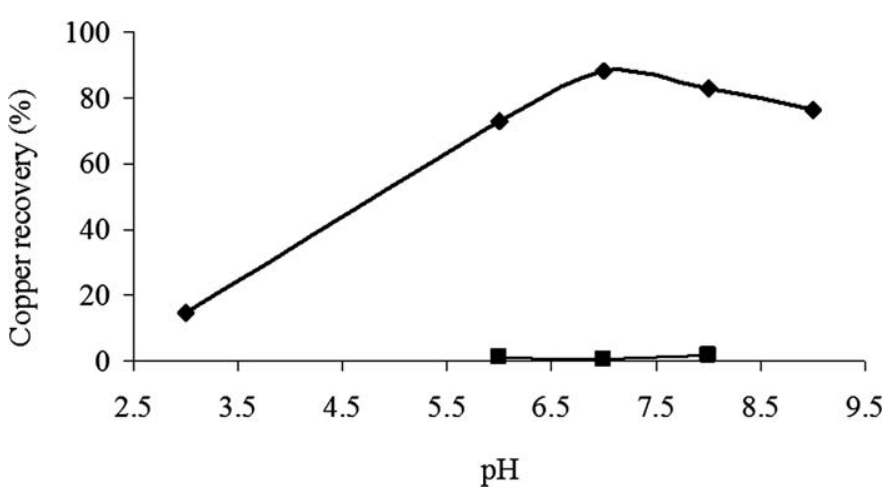

FIG. 2. Effect of $\mathrm{pH}$ on the extraction of $40 \mu \mathrm{g} \mathrm{L}^{-1} \mathrm{Cu}(\mathrm{II})$ using the disk: (a) with immobilized reagent $(\Delta)$; (b) without reagent $(\boldsymbol{\square})\left(V_{\text {sample }}=500\right.$ $\mathrm{mL} ; V_{\text {eluant }}=10 \mathrm{~mL}$ of $1 \mathrm{~mol} \mathrm{~L}-1 \mathrm{HNO}_{3}$; FAAS measurements).

retention of copper ions, while the modified SDB-XC disks with $2-\mathrm{HBBH}$ were capable of retaining $\mathrm{Cu}(\mathrm{II})$ ions on the surface.

The optimization process was developed using a twostage strategy. First, previous studies of chemical parameters such as $\mathrm{pH}$, amount of reagent, and type of buffer were carried out using the univariate method in order to achieve high efficiency and good selectivity. Retained $\mathrm{Cu}(\mathrm{II})$ ions extracted in these experiments were determined using FAAS. Then, to select the optimum conditions for $\mathrm{pH}$, amount of ligand immobilized on the disk and time for immobilization, a reduced factorial design (fractional factorial design $3^{3-1}$ ) was employed. With this kind of design, the factors can be efficiently evaluated using a small fraction of the experiments of the full factorial design. For the optimization experiments, retained $\mathrm{Cu}(\mathrm{II})$ ions were determined using diffuse reflectance measurements.

Preliminary Studies for the Solid Phase Extraction of $\mathrm{Cu}$ (II) Using Flame Atomic Absorption Spectrophotometer (FAAS). Preliminary studies of the influence of variables on the copper ions extraction were carried out with FAAS as the measurement technique after acid elution of metal ion from the disk.

Effect of $\mathrm{pH}$ on the Solid Phase Extraction of Cu(II). The $\mathrm{pH}$ of the medium plays a key role in the extraction procedure improving the ligand-metal complex reaction efficiency. ${ }^{3}$ The influence of the $\mathrm{pH}$ on the recovery of copper was studied in the range 3 to 9 by passing $500 \mathrm{~mL}$ solutions of $20 \mu \mathrm{g} \mathrm{Cu}(\mathrm{II})$ through the modified membrane disk. The $\mathrm{pH}$ values of the solutions were adjusted with $50 \mathrm{~mL}$ of Hydrion ${ }^{\circledR}$ buffer. A solution of $2-\mathrm{HBBH}$ was passed through the disk. We used $10 \mathrm{~mL}$ of $1 \mathrm{~mol} \mathrm{~L}^{-1}$ nitric acid for the acid elution step, obtaining a preconcentration factor of 50 . The plot of copper recovery versus $\mathrm{pH}$ showed $\mathrm{pH}$ values close to 7 as the optimum condition (Fig. 2). A neutral $\mathrm{pH}$ value is considered appropriate for biological and environmental applications.

Effect of Amount of Ligand 2-Hydroxybenzaldehyde Benzoylhydrazone (2-HBBH). The extraction of copper at $\mathrm{pH} 7$ was studied with each SDB disk modified with different quantities of ligand (Fig. 3). The minimum quantity of $2-\mathrm{HBBH}$ required to achieve the maximum recovery of copper (around $85 \%$ ) was $1.25 \mathrm{mg}$. In order to

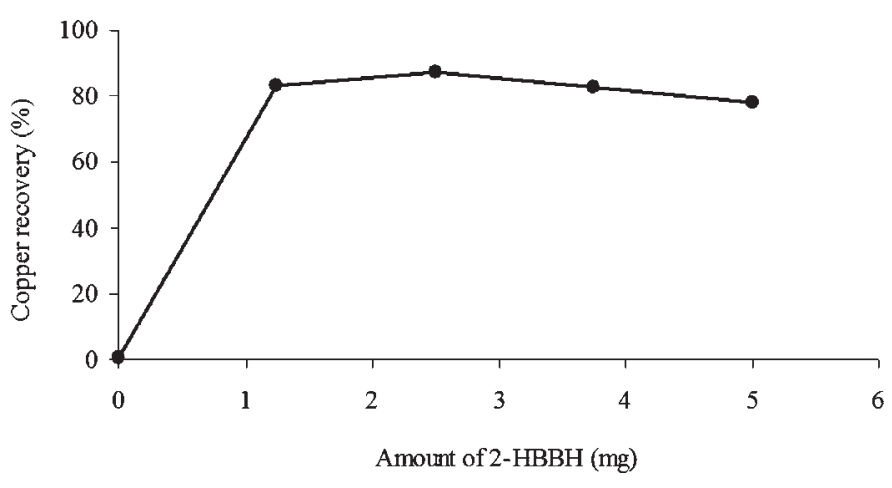

FIG. 3. Effect of the amount of ligand on the extraction of $40 \mu \mathrm{g} \mathrm{L}^{-1}$ $\mathrm{Cu}(\mathrm{II})$ using the modified disk $\left(V_{\text {sample }}=500 \mathrm{~mL} ; V_{\text {eluant }}=10 \mathrm{~mL}\right.$ of $1 \mathrm{~mol}$ $\mathrm{L}^{-1} \mathrm{HNO}_{3}$; FAAS measurements).

assure that there was enough ligand to form a complex with copper ions, $2.5 \mathrm{mg}$ was selected as the adequate amount of 2-HBBH for FAAS measurements.

Effect of Buffer Composition Used to Adjust the Sample $\mathbf{p H}$ Value. In order to choose the proper buffer for the extraction of copper ions, the $\mathrm{pH}$ of the solution was adjusted using five different buffers (Table II). For this experiment, $500 \mathrm{~mL}$ of solution containing $20 \mu \mathrm{g}$ of $\mathrm{Cu}$ (II) was adjusted to $\mathrm{pH} 7$ by adding $50 \mathrm{~mL}$ of each buffer solution. Each solution was passed through a disk containing $2.5 \mathrm{mg}$ of $2-\mathrm{HBBH}$. We used $10 \mathrm{~mL}$ of $1 \mathrm{~mol} \mathrm{~L}^{-1}$ nitric acid for the acid elution step, obtaining a preconcentration factor of 50 . The best recoveries were achieved using both $\mathrm{KH}_{2} \mathrm{PO}_{4} / \mathrm{NaOH}$ and Hydrion buffers.

Optimization of Variables Using Diffuse Reflectance Measurements. Using the values of suitable parameters obtained in the preliminary studies, the new colorimetric-solid phase extraction method was investigated using diffuse reflectance measurements. The largest difference in reflectance before and after reaction with $\mathrm{Cu}(\mathrm{II})$ was observed at $400 \mathrm{~nm}$ and adjusting the $\mathrm{pH}$ with $\mathrm{KH}_{2} \mathrm{PO}_{4} / \mathrm{NaOH}$. The color of the disk changes with the concentration of copper from white to green, being detected with diffuse reflectance measurements using optical fiber.

Due to its relevance and important effect in optical sensors, the $\mathrm{pH}$, amount of ligand immobilized onto the disk, and time for immobilization were evaluated. In order to determine the influence of these factors, a fractional factorial design $3^{3-1}$ was performed. It has the advantages of identifying and isolating the significant factors with a minimum number of experiments. ${ }^{27}$ To the best of our knowledge, this statistical method has never been applied to C-SPE processes.

TABLE II. Influence of the composition of buffer solution used to adjust the sample $\mathrm{pH}$ value on copper recovery $\left(V_{\text {sample }}=500 \mathrm{~mL}\right.$; $V_{\text {buffer }}=\mathbf{5 0} \mathrm{mL}$ ).

Buffer solution added $(\mathrm{pH} 7)$

Recovery (\%)

Hydrion-buffer

$\mathrm{HNO}_{3}\left(1 \mathrm{~mol} \mathrm{~L}{ }^{-1}\right) / \mathrm{NH}_{3}\left(1 \mathrm{~mol} \mathrm{~L}{ }^{-1}\right)$ 88.06

HEPES (0.5 mol L $\left.{ }^{-1}\right)$

$\mathrm{KH}_{2} \mathrm{PO}_{4} / \mathrm{NaOH}\left(0.5 \mathrm{~mol} \mathrm{~L}^{-1}\right)$

74.35

55.15

88.73

PIPES (0.05 $\mathrm{mol} \mathrm{L}^{-1}$ ) 
TABLE III. Variables and levels of the fractional factorial design $3^{3-1}\left(V_{\text {sample }}=50 \mathrm{~mL}\right.$; $V_{\text {buffer }}=5 \mathrm{~mL}$ of $0.5 \mathrm{~mol} \mathrm{~L}^{-1} \mathrm{KH}_{2} \mathrm{PO}_{4} / \mathrm{NaOH}$; $\mathrm{C}_{\mathrm{Cu}(\mathrm{II})}=2.5 \mathrm{mg} \mathrm{L}^{-1}$ ).

\begin{tabular}{llcc}
\hline Variable & -1 & 0 & +1 \\
\hline $\mathrm{pH}$ & 5 & 7 & 9 \\
Immobilization time $(\mathrm{min})$ & 5 & 10 & 15 \\
Amount of ligand immobilized $(\mathrm{mg})$ & 0.25 & 3.25 & 6.25 \\
\hline
\end{tabular}

The three variables studied were coded at three levels, high, medium, and low, denoted using (+1), (0), and $(-1)$, respectively. Selected levels of each variable were chosen according to the data from preliminary experiments (Table III). In total ten experiments were carried out, including two repetitions of the central point. The response variable evaluated with the fractional factorial design was the reflectance signal of $\mathrm{Cu}-2-\mathrm{HBBH}$ complex. No significant parameters were kept fixed: volume of sample solution, $50 \mathrm{~mL}$; buffer concentration $\left(\mathrm{KH}_{2} \mathrm{PO}_{4} / \mathrm{NaOH}\right), 0.5 \mathrm{M}$; and copper concentration, $2.5 \mathrm{mg}$ $\mathrm{L}^{-1}$. Table IV shows the matrix of the experimental design and the respective response variable. Statistical analysis was performed using Statistica 7.0 for the fractional factorial design $3^{3-1} \cdot{ }^{28}$ The interpretation of the factorial design using the Pareto chart (Fig. 4) demonstrated that $\mathrm{pH}$ (Var 1) and amount of ligand (Var 3) showed significant effects (at 95\% confidence level). On one hand, amount of ligand immobilized showed a linear positive effect over the reflectance signal. On the other hand, $\mathrm{pH}$ showed a quadratic positive effect. Due to its nonsignificant effect, the immobilization time (Var 2) was fixed at an intermediate value so that the experiments were not long. Response surfaces were represented graphically in a spherical domain. Diffuse reflectance intensity was taken as the response signal in the three response surfaces, keeping one variable at its optimum level and the other two varying within the experimental ranges (Fig. 5). The effect of the variables $\mathrm{pH}$ and immobilization time over the reflectance is shown in Fig. $5 \mathrm{a}$, where the amount of 2-HBBH was held at $6.25 \mathrm{mg}$, according to the results of the Pareto chart. The effect of $\mathrm{pH}$ and amount of ligand at a constant immobilization time (10 min) is shown in Fig. 5b. Finally, Fig. 5c shows the effect between immobilization time and amount of ligand using $\mathrm{pH}$ as the medium value of the interval $\mathrm{pH}$

TABLE IV. Design matrix and the results of the fractional factorial design $3^{3-1}\left(V_{\text {sample }}=50 \mathrm{~mL} ; V_{\text {buffer }}=5 \mathrm{~mL}\right.$ of $0.5 \mathrm{~mol} \mathrm{~L}^{-1} \mathrm{KH}_{2} \mathrm{PO}_{4} /$ $\left.\mathrm{NaOH} ; \mathrm{C}_{\mathrm{Cu}(\mathrm{II})}=2.5 \mathrm{mg} \mathrm{L}^{-1}\right)$.

\begin{tabular}{crccc}
\hline Experiment & $\mathrm{pH}$ & $\begin{array}{c}\text { Immobilization } \\
\text { time }\end{array}$ & $\begin{array}{c}\text { Amount } \\
\text { of ligand }\end{array}$ & $\begin{array}{c}\text { Reflectance } \\
\text { signal }(400 \mathrm{~nm})\end{array}$ \\
\hline 2 & -1 & 0 & +1 & 0.80 \\
5 & 0 & 0 & 0 & 0.81 \\
3 & -1 & +1 & 0 & 0.57 \\
8 & +1 & 0 & -1 & 0.43 \\
4 & 0 & -1 & +1 & 0.87 \\
7 & +1 & -1 & 0 & 0.53 \\
6 & 0 & +1 & -1 & 0.47 \\
9 & +1 & +1 & +1 & 0.80 \\
1 & -1 & -1 & -1 & 0.43 \\
10 & 0 & 0 & 0 & 0.80 \\
\hline
\end{tabular}

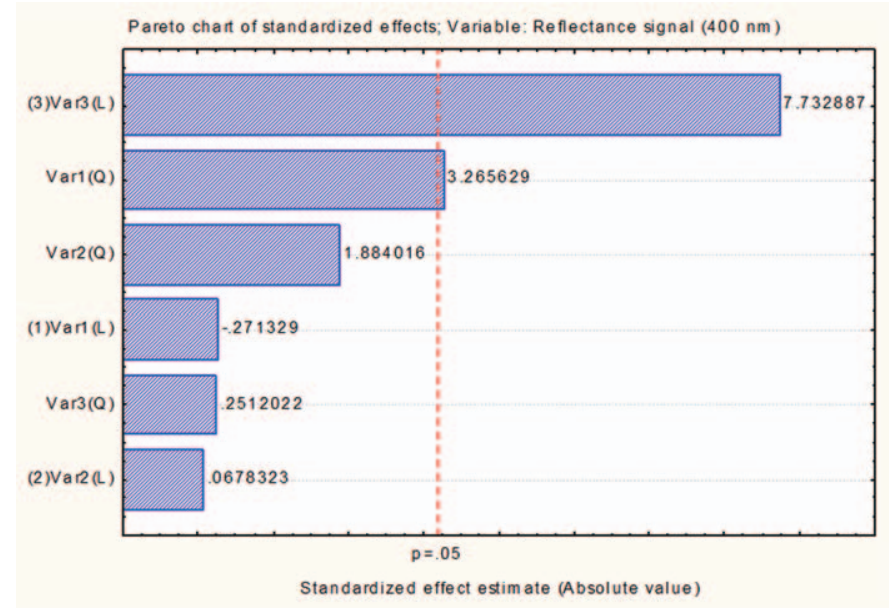

FIG. 4. Pareto chart of standardized effects for fractional factorial design using reflectance signal as response variable (Var 1, pH; Var 2, immobilization time; Var 3, amount of ligand).

7). Such plots were helpful in determining the optimal experimental conditions. The results indicated that the higher the amount of ligand, the higher the reflectance signal in the studied experimental domain. As far as immobilization time and $\mathrm{pH}$ are concerned, both showed better results at the medium values of the interval ranges studied.

Hence, the optimum conditions selected for the sensing of copper ions were $\mathrm{pH}=7,10 \mathrm{~min}$ as immobilization time, and $6.25 \mathrm{mg}$ for the amount of ligand. As can be seen, the optimum amount of ligand is higher than the quantity employed in the preliminary studies. This can be explained using the lower sensitivity of the diffuse reflectance measurements compared with atomic absorption.

Lifetime and Reusability of the Sensor. The study of lifetime of the sensor was accomplished and no significant differences in the optical properties of the disk were found over several days. The diffuse reflectance signal was recorded at a wavelength of $400 \mathrm{~nm}$ as a function of time when the sensing layer with $6.25 \mathrm{mg}$ of 2-HBBH was exposed to $1 \mathrm{mg} \mathrm{L}^{-1} \mathrm{Cu}(\mathrm{II})$ at $\mathrm{pH}$ 7.0. It was observed that there was no decrease in the reflectance intensity of the C-SPE disk after repetitive measurements together with no leaching of 2-HBBH. Thus, the results obtained showed a high degree of stability of the sensing membrane. For this reason, the proposed sensor can be used to extract and retain copper ions on-site and then analyze the disk in the laboratory several days after collection without losing its characteristics.

The reversibility of the sensor in solution was reported in our previous paper. ${ }^{24}$ It was demonstrated that the binding between 2-HBBH and $\mathrm{Cu}(\mathrm{II})$ is really chemically reversible after addition of ethylenediaminetetraacetic acid (EDTA) to the solution. However, for trace analysis in a solid support, the use of a new modified disk is recommended for each measurement in order to avoid subsequent contaminations. ${ }^{20}$

Analytical Features of the Sensor. Under the optimum experimental conditions, the analytical parameters of the proposed method were determined. The calibration graph for $\mathrm{Cu}$ (II) was linear over the range of 0 to $2.5 \mathrm{mg} \mathrm{L}^{-1}$ of 


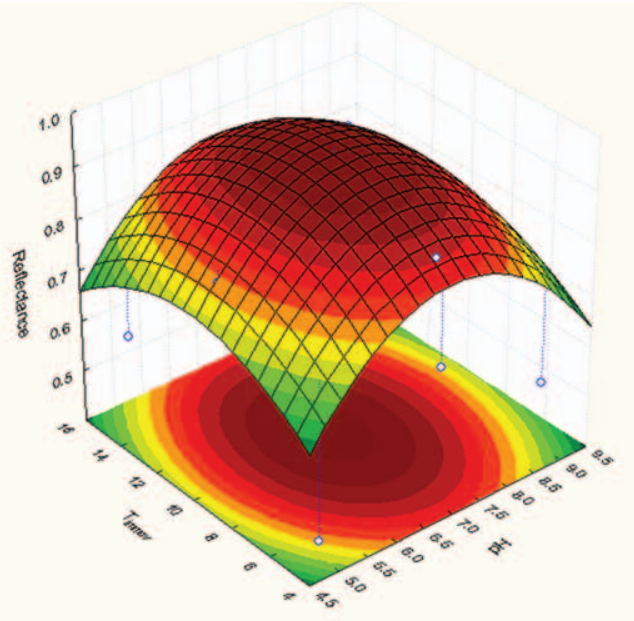

a)
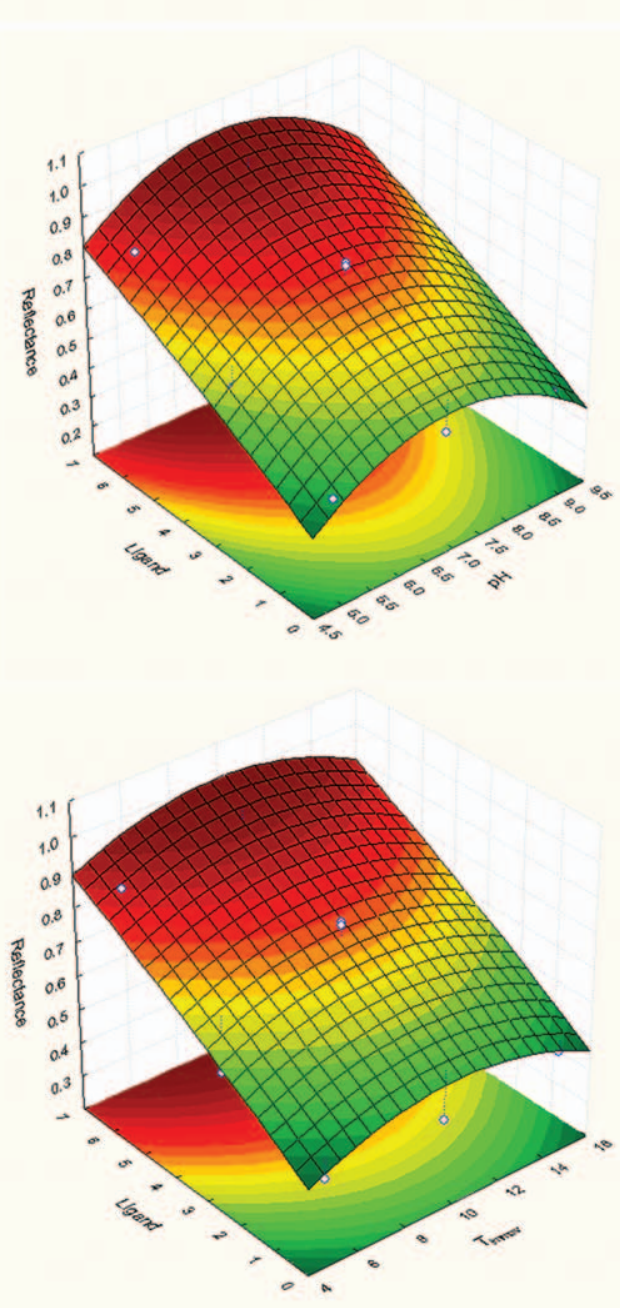

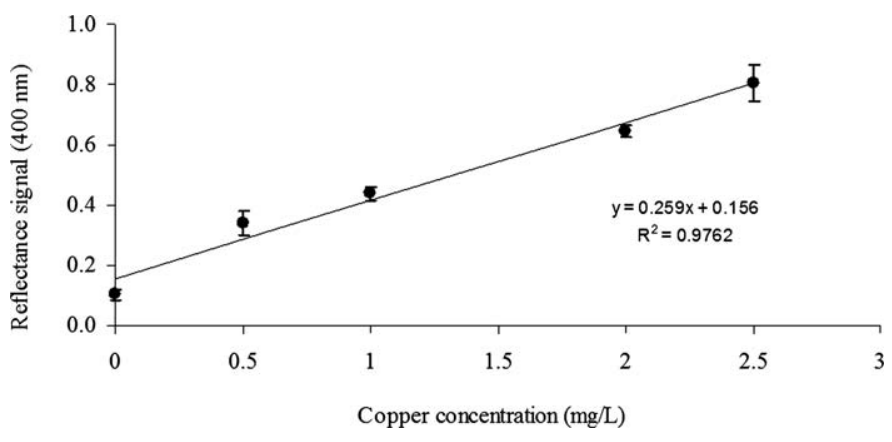

FIG. 6. Calibration curve for different $\mathrm{Cu}$ (II) concentrations using the optimum conditions at $400 \mathrm{~nm}$ using diffuse reflectance measurements $\left(V_{\text {sample }}=50 \mathrm{~mL} ; V_{\text {buffer }}=5 \mathrm{~mL}\right.$ of $0.5 \mathrm{~mol} \mathrm{~L}^{-1} \mathrm{KH}_{2} \mathrm{PO}_{4} / \mathrm{NaOH}$ at $\mathrm{pH}=7$; $6.25 \mathrm{mg} 2-\mathrm{HBBH})$.

where $\sigma$ is the blank standard deviation and $m$ is the slope of the calibration graph, was found to be $0.21 \mathrm{mg} \mathrm{L}^{-1}$ of $\mathrm{Cu}(\mathrm{II})(\mathrm{n}=7)$. The repeatability of the C-SPE sensing layer was also evaluated through the relative standard deviation (RSD) of six replicate measurements of a solution containing $1 \mathrm{mg} \mathrm{L}^{-1}$ of copper ion. The RSD was found to be $4.87 \%$, and the precision of the method was $4.01 \%$ at a significance level of $95 \%(n=6)$.

Interference Study. Under optimum conditions, the effects of various foreign ions on the determination of $\mathrm{Cu}(\mathrm{II})$ were examined using the proposed C-SPE method. Possible interference by matrix of water samples was investigated by adding different inorganic salts and metals present in seawater to a solution containing $1 \mathrm{mg} \mathrm{L}^{-1}$ of $\mathrm{Cu}(\mathrm{II})$. The possible interferences of inorganic salts, such as $\mathrm{KCl}, \mathrm{NaHCO}_{3}, \mathrm{NaCl}, \mathrm{NaF}$, $\mathrm{MgCl}_{2}, \mathrm{Na}_{2} \mathrm{SO}_{4}, \mathrm{H}_{3} \mathrm{BO}_{3}, \mathrm{KBr}$, and $\mathrm{SrCl}_{2}$ were evaluated using the normal concentration found in seawater. ${ }^{30}$ On the other hand, the possible interference of some inorganic cations, such as $\mathrm{Ca}(\mathrm{II}), \mathrm{Cd}(\mathrm{II}), \mathrm{Zn}(\mathrm{II}), \mathrm{K}(\mathrm{I})$, $\mathrm{Mg}(\mathrm{II}), \mathrm{Na}(\mathrm{I}), \mathrm{Pb}(\mathrm{II}), \mathrm{Fe}(\mathrm{II})$, and $\mathrm{Fe}(\mathrm{III})$ were evaluated at $1 \mathrm{mg} \mathrm{L}^{-1}$. It was found that the method was free from interference of the saline matrix, being only affected by $\mathrm{Fe}(\mathrm{III})$ and $\mathrm{Zn}(\mathrm{II})$ at $1 \mathrm{mg} \mathrm{L}^{-1}$.

Evaluation of Fluorescence Quenching Using Cu-2Hydroxybenzaldehyde Benzoylhydrazone (Cu-2HBBH) Sensor. Due to the fact that fluorescence detection methods can be more selective and sensitive over other light-based methods such as reflectance, ${ }^{31,32}$ fluorescence analysis was performed as an alternative form of measurement of the analyte on the solid surface (for copper analysis) and compared with the reflectance measurements. In this manner, the optical fiber was placed in direct contact onto the disk under darkness to acquire the fluorescence spectrum. The fluorescence intensity was recorded at $447 \mathrm{~nm}$ using an excitation wavelength of $360 \mathrm{~nm}$. Under the optimum conditions, the fluorescence quenching data were observed, and the data were analyzed using the Stern-Volmer relationship, given below:

$$
F_{0} / F=1+K_{\mathrm{SV}}[Q]
$$

where $F$ and $F_{0}$ are the fluorescence intensities of the reagent in the presence and absence of copper ion, respectively. [Q] is the copper ion concentration 

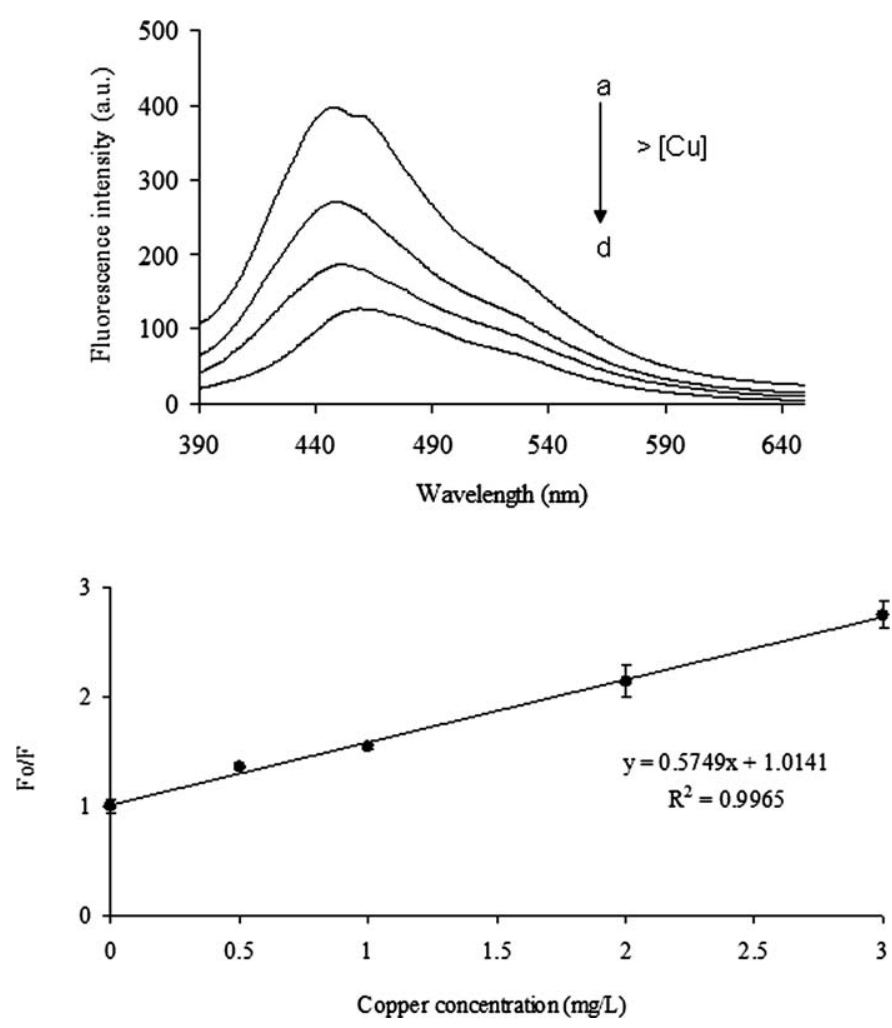

FIG. 7. Top: Fluorescence emission spectra of $2-\mathrm{HBBH}$ in the presence of different concentrations of $\mathrm{Cu}$ (II) ions $\left(\mathrm{mg} \mathrm{L}^{-1}\right)$ : (a) 0 ; (b) 1 ; (c) 2; (d) 4; Bottom: Stern-Volmer plot of 2-HBBH with increasing concentrations of $\mathrm{Cu}$ (II) $\left(V_{\text {sample }}=50 \mathrm{~mL}\right.$; $V_{\text {buffer }}=5 \mathrm{~mL}$ of $0.5 \mathrm{~mol} \mathrm{~L}^{-1} \mathrm{KH}_{2} \mathrm{PO}_{4} / \mathrm{NaOH}$ at $\mathrm{pH}=7 ; 6.25 \mathrm{mg} 2-\mathrm{HBBH})$. Excitation and emission wavelengths were 360 and $447 \mathrm{~nm}$, respectively.

(quencher) and $K_{\mathrm{SV}}$ is the Stern-Volmer quenching constant. The calibration graph for $\mathrm{Cu}(\mathrm{II})$ was linear over the range of 0 to $3 \mathrm{mg} \mathrm{L}^{-1}$ of $\mathrm{Cu}(\mathrm{II})$ with a correlation coefficient and equation of the linear regression being $R^{2}$ $=0.996$ and $F_{0} / F=0.575 Q\left(\mathrm{mg} \mathrm{L}^{-1}\right)+1.014$, respectively (Fig. 7). Detection limit evaluated, as indicated previously, was found to be $0.28 \mathrm{mg} \mathrm{L}^{-1}$ of $\mathrm{Cu}(\mathrm{II})$. It can be concluded that the combination of SPE onto a modified membrane disk with reflectance or fluorescence spectroscopy can be applied with good results.

\section{CONCLUSION}

A simple, easy, and inexpensive sensor based on the immobilization of 2-HBBH onto SDB-XC disks for the sensing of $\mathrm{Cu}(\mathrm{II})$ in waters has been described. The sensor is characterized using the rapidity of the analysis and the possible portability of the system.

The detection limit and the calibration curve can allow the use of the sensor to analyze water samples that are reasonably contaminated with copper. Thus, successful applications could be in using the sensor as an alarm for rapid monitoring of drinking water or in the waste stream of a copper-based industry where the concentration of copper is not allowed to exceed a maximum level. The combination between the C-SPE method and diffuse reflectance or fluorescence spectroscopy for the determination of copper presented in this paper has been shown to be a useful tool for further analytical applications. This field opens extensive possibilities for the determination of metal ions in aqueous samples, and several studies in this direction are now in progress in our laboratory.

\section{ACKNOWLEDGMENTS}

The authors would like to gratefully thank "Junta de Andalucia" for the fellowship of EEB, the University of Cadiz for the support of this work, and the University of Manchester for providing facilities for the research. This work was supported from funds of Spanish Agency of International Cooperation: Program of Scientific Cooperation and Interuniversity Investigation (PCl-Mediterranean) with the Project $\mathrm{A} /$ $030523 / 10$ and $A 1 / 041491 / 11$. The authors gratefully acknowledge the comments by the anonymous reviewers for improving the paper.

1. P.C. Onianwa, A.O. Adeyemo, O.E. Idowu, E.E. Ogabiela. "Copper and Zinc Contents of Nigerian Foods and Estimates of the Adult Dietary Intakes". Food Chem. 2001. 72(1): 89-95.

2. S. Tokalioglu, F. Gürbüz. "Selective Determination of Copper and Iron in Various Food Samples by the Solid Phase Extraction". Food Chem. 2010. 123(1): 183-187.

3. G. Xiang, Y. Zhang, X. Jiang, L. He, L. Fan, W. Zhao. "Determination of Trace Copper in Food Samples by Flame Atomic Absorption Spectrometry After Solid Phase Extraction on Modified Soybean Hull". J. Hazard. Mater. 2010. 179(1-3): 521-525.

4. EPA. "United States Environmental Protection Agency: EPA 816-F09-004". 2012. http://water.epa.gov/drink/contaminants/index.cfm [accessed Jan 13 2014].

5. M.F. Buchman. "NOAA Screening Quick Reference Tables, NOAA OR\&R Report 08-1". Seattle WA:. Office of Response and Restoration Division, National Oceanic and Atmospheric Administration, 2012.http://archive.orr.noaa.gov/index.php [accessed Jan 13 2014]

6. J. Curylo, W. Wardencki, J. Namiesnik. "Green Aspects of Sample Preparation-A Need for Solvent Reduction". Pol. J. Environ. Stud. 2007. 16(1): 5-16.

7. J. Namiesnik, P. Szefer, editors. "Analytical Measurements in Aquatic Environments". Taylor and Francis Group, 2010.

8. R.E. Clement, P.W. Yang. "Environmental Analysis". Anal. Chem. 2001. 73(12): 2761-2790.

9. C. Cámara, C. Pérez-Conde, M.C. Moreno-Bondi, C. Rivas. "Fiber Optical Sensors Applied to Field Measurements". Tech. Instrum. Anal. Chem. 1995. 17(1): 165-193.

10. M.B. Gholivand, P. Niroomandi, A. Yari, M. Joshagani. "Characterization of an Optical Copper Sensor Based on $N, N^{\prime}$-bis(salycilidene)-1,2-phenylenediamine". Anal. Chim. Acta. 2005. 538(1-2): 225-231.

11. S. Armenta, S. Garrigues, M. de la Guardia. "Green Analytical Chemistry". TrAC, Trends Anal. Chem. 2008. 27(6): 497-511.

12. N.C. Dias, M.D. Porter, J.S. Fritz. "Principles and Applications of Colorimetric Solid-Phase Extraction with Negligible Depletion". Anal. Chim. Acta. 2006. 558(1-2): 230-236.

13. H. Filik, D. Aksu, R. Apak, I. Sener, E. Kilic. "An Optical Fibre Reflectance Sensor for p-Aminophenol Determination Based on Tetrahydroxycalix[4]arene as Sensing Reagent". Sens. Actuators, B. 2009. 136(1): 105-112.

14. D.B. Gazda, J.S. Fritz, M.D. Porter. "Determination of Nickel(II) as the Nickel Dimethylglyoxime Complex Using Colorimetric Solid Phase Extraction". Anal. Chim. Acta. 2004. 508(1): 53-59.

15. G. Kortum. Reflectance Spectroscopy_Principles, Methods, Applications. New York: Springer, 1969. Pp. 106-116.

16. H. Filik, D. Aksu, R. Apak, I. Boz. "Rapid Sensing of Molibdenum by Combined Colorimetric Solid-Phase Extraction-Reflectance Spectroscopy". Sens. Actuators, B. 2009. 141(2): 491-497.

17. M.P. Arena, M.D. Porter, J.S. Fritz. "Rapid, Low Level Determination of Silver(I) in Drinking Water by Colorimetric-Solid-Phase Extraction". Anal. Chim. Acta. 2003. 482(2): 197-207.

18. N. Mahendra, P. Gangaiya, S. Sotheeswaran, R. Narayanaswamy. "Investigation of a Fibre Optic Copper Sensor Based on Immobilised@A-Benzoinoxime (Cupron)". Sens. Actuators, B. 2003. 90(1-3): 118-123.

19. J.S. Fritz, M.P. Arena, S.A. Steiner, M.D. Porter. "Rapid Determination of lons by Combined Solid-Phase Extraction-Diffuse Reflectance Spectroscopy". J. Chromatogr., A. 2003. 997(1-2): 41-50. 
20. H. Filik, Z. Yanaz. "A Sensitive Method for Determining Total Vanadium in Water Samples Using Colorimetric-Solid-Phase Extraction-Fiber Optic Reflectance Spectroscopy". J. Hazard. Mater. 2009. 172(2-3): 1297-1302.

21. A.A. Hill, R.J. Lipert, M.D. Porter. "Determination of Colloidal and Dissolved Silver in Water Samples Using Colorimetric Solid-Phase Extraction". Talanta. 2010. 80(5): 1606-1610.

22. Z. Yanaz, H. Filik, R. Apak. "Development of an Optical Fibre Reflectance Sensor for Lead Detection Based on Immobilised Arsenazo III". Sens. Actuators, B. 2010. 147(1): 15-22.

23. M.M. Bradley, L.M. Siperko, M.D. Porter. "Colorimetric-Solid Phase Extraction Method for Trace Level Determination of Arsenite in Water". Talanta. 2011. 86(1): 64-70.

24. E. Espada-Bellido, M.D. Galindo-Riaño, M. García-Vargas, R. Narayanaswamy. "Selective Chemosensor for Copper lons Based on Fluorescence Quenching of a Schiff-Base Fluorophore". Appl. Spectrosc. 2010. 64(7): 727-732.

25. M. Díaz-de Alba, M.D. Galindo-Riaño, M. García-Vargas. "Solid Phase Extraction of Copper Traces Using Poly(Styrene-Divinylbenzene) Membrane Disks Modified with Pyridoxal Salicyloylhydrazone in Water Samples". Talanta. 2012. 100(1): 432-438.
26. E. Espada-Bellido, M.D. Galindo-Riaño, A. Aouarram, M. GarcíaVargas. "Applicability of 2-Hydroxybenzaldehyde Benzoylhydrazone in the Determination of Trace Metals by Adsorptive Cathodic Stripping Voltammetry: Relevancy of Simultaneous Determinations". Anal. Sci. 2009. 25(7): 903-909.

27. P.W. Araujo, R.G. Brereton. "Experimental Design I. Screening" TrAC, Trends Anal. Chem. 1996. 15(1): 26-31.

28. STATISTICA. Data Analysis Software System, version 7, 2004. Statsoft, Inc.

29. International Union of Pure and Applied Chemistry. IUPAC Compendium of Chemical Terminology (Gold Book). Compiled by A.D. McNaught and A. Wilkinson. Oxford, UK: Blackwell Scientific Publications, 1997. $2^{\text {nd }}$ ed

30. K. Grasshoff, M. Ehrhardt, K. Kremling. Methods of Seawater Analysis. Weinheim, Germany: Verlag Chemie, 1983. 2nd ed. Pp. 491.

31. L. Prodi, F. Bolletta, M. Montalti, N. Zaccheroni. "Luminescent Chemosensors for Transition Metal Ions". Coord. Chem. Rev. 2000. 205(1): 59-83.

32. R. Martínez-Máñez, F. Sancenón. "Fluorogenic and Chromogenic Chemosensors and Reagents for Anions". Chem. Rev. 2003 103(11): 4419-4476. 